\title{
WALERY Sustow \\ CONSIDERATION OF THE SPECIFICS \\ OF UNDERSTANDING TEXTUAL \\ COMMUNIQUÉS IN DESIGNING DIALOGUES \\ WITH A USER OF AN INFORMATION \\ SYSTEM
}

Abstract

Keywords
The paper presents a proposal to take into account the language comprehension paradigm in an attempt to improve the design methodology of human-computer dialogues. It is assumed that the user treats a system as a subject, i.e. perceives communication with the system as a kind of discourse and intuitively treats it as cognition of the world through a fixed image of objective linguistic signs. Due to the fact that every end-user of a computer system has an individual linguistic competence, thesaurus, habits, previous experiences, one can never guarantee that identical semantic references arise in a variety of audiences. The situation becomes more stable if one considers the communication aspect of comprehension on the basis of practice (familiarity of things). It may be expected that a qualified professional user will commit fewer errors, caused by a poor dialogue understanding while interacting with the system. Therefore, the main task of a designer is to speed up and facilitate the learning process, which can be achieved by running the process of constructive rational understanding.

information system, human-computer interaction, phenomenon of understanding, language comprehension paradigm, quality of a dialogue 


\section{Introduction}

This article presents a proposal of considering the paradigm of understanding in a methodology of designing dialogues led with the user of an information system (IS). It is assumed that the user treats the system subjectively which means he/she perceives the communication with the system as a kind of a discourse and intuitively treats it as cognition of ideal images recorded via objective linguistic signs.

Since the individual user has unique linguistic competence, thesaurus, habits, and previous experiences, there is never a guarantee that different individuals will create identical semantic references. The situation becomes more stable while taking into account the aspect of understanding a communiqué (message) on the basis of practice and knowledge of the subject matter. One may expect that a competent professional user will make fewer mistakes during the communication with the system caused by misunderstanding the dialogue with the system. Therefore, the main task of a IS designer is to make the user's learning process faster and easier. This can be achieved by initiating a constructive process of rational reasoning.

\section{Understanding - an efficiency factor in IS usage}

Presently, information systems are being used on a massive scale in an organization's management. The objective of these systems is to gather, store, send and process data in order to make the right decisions and to manage a company efficiently [21, 7]. The level of intelligence of management systems is constantly increasing. Modern systems processing information realize more and more functions which have been performed exclusively by humans. There is an already existing software enabling the analysis of cause-effect relations and drawing new knowledge from gathered facts. The core of data processing procedures taking place in intelligent management systems may be shown as in Fig. 1.

Monitoring an area of interest (action fields) gives, within the system, raw data (facts) concerning the observed parameters describing the area. The list of parameters (features of the field) under scrutiny, is strictly specified on the basis of a conceptual model of a domain. It is necessary to emphasize that information about the domain is not related with the value of the observed parameters but rather with the dynamics of these changes. One may associate them metaphorically with juxtaposition (comparison) reports generated by a management system.

In order to protect the user of the system (decision-maker) against information noise, the system should be equipped with filters in accordance with the objective of the enterprise. Filtered information, in the context of the objective and previously gathered knowledge about a domain, is to serve as the basis for forecasting processes happening in the domain. It will make predicting changes within the interest area and conscious managing of the area possible.

The user's understanding of system processes and events is a necessary success factor in computer-aided management. The conceptual approach to the description 


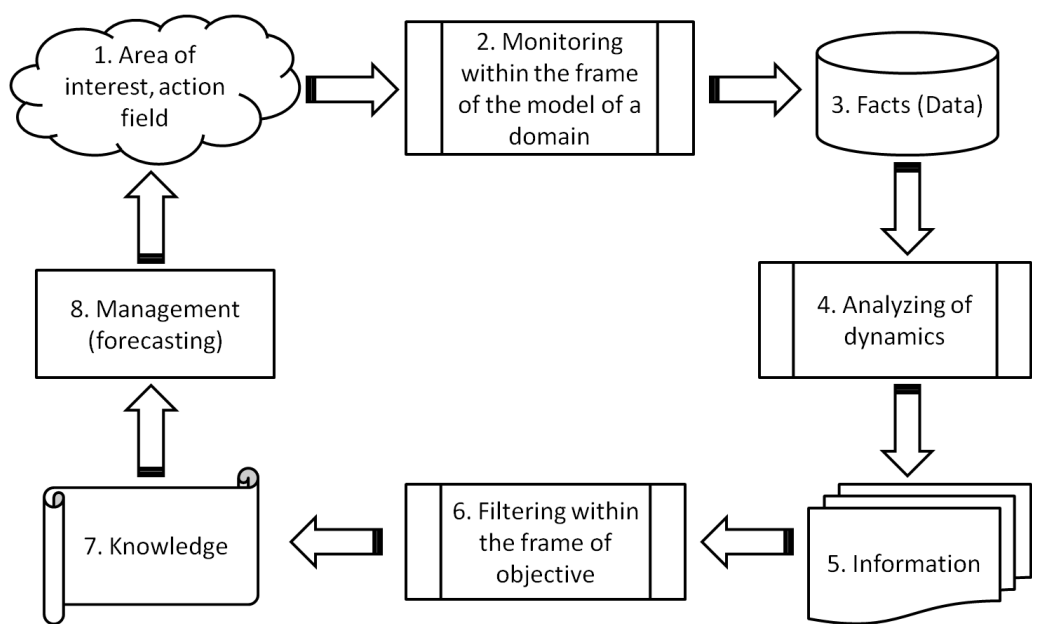

Figure 1. Intelligent management system data processing chart.

of the potential interaction between an individual and the environment (in our case the system) may be based on the concept of affordances, introduced by a psychologist J. Gibson [16]. According to Gibson, affordances are opportunities to affect objects of the environment. Affordances were defined as all opportunities for action present in an environment, possible to be measured objectively, and independent from the unique skills of specific individuals to recognize them, but always staying in a relation with them and consequently - dependent on their abilities. Nowadays, affordances are considered dependent on not only the physical capabilities of an individual but also on his/her intentions, hierarchy of values, objectives and experiences.

Donald Norman [24] specified the meaning of the concept of affordances in the context of computer environments as a conscious possibility of actions based on human-computer interaction theory (HCI). His new approach defines affordances as possibilities of action which are recognized by a software and computer equipment user. The concept of affordance became popular in designing interaction. It is worth emphasizing that the types of user interactions with the information system via graphic interface are based on not only affordances of windows and controls, presented as dynamic images on a screen. The approach to creating new interfaces as a kind of art bears little credibility because it stands in opposition to the main objective of a designer of industrial patterns which is to make the use of an object easier.

The popular concept of windows and controls GUI is far from perfect as it does not always enable creating a user-friendly interface. For instance, the construction and work of such a control as a slider disagrees with the basic psychological rule of human perception: a human can have only one active point of attention, while in case of the slider it is necessary to pay attention to two objects - the control proper and the area which is being moved. It is against human nature. 
It seems that the core of a good interface is the right metaphor [18]. Context and situation suggested to the user with the help of the metaphor should be familiar to him/her and easily associated. GUI designer conscious use of the right metaphor will make it easy for the user to understand the interpretation and understanding of the state of an application. It will not require the constant use of a manual and it will create the feeling of psychological comfort. Within the frame of the accepted metaphor it is good to work out a relevant set of controls which may constitute a specific alphabet. Moreover, it is worth working out a general visual style in order to create a pleasant, ergonomic sight of the interface. A conceptual design of the dialogue windows should be based on the idea of an interface environment. In fact, fulfilling these design requirements assumes that the user will be immersed into the IS interface environment and he/she will follow a typical social human behavior [16] which may, when simplified, be predictable already at the design stage from an actionreaction perspective.

Table 1 presents some examples of the incomprehensible software dialogue fragments from well known applications. They illustrate problems, which makes user difficult to understand the proper operation. As you can see, the linguistic basis for the confusion may be: not precise vocabulary, incomplete definition of context, undermine the coherence of expression and others.

\section{Paradigm of understanding}

The phenomenon of understanding, defined globally and at a high level of abstraction, may be specified as a psychological state of an individual relating to a correct perception or an interpretation of a phenomenon or fact, recognized in certain fields. In the literature regarding the paradigm of understanding there are three groups of theories [4] presenting various approaches to understanding: objective, subjectiveobjective and subjective. In the objective theories priority is given to structural and semantic analysis and understanding is ontologized and compared to the object proper. Understand, within the frames of these theories, means to specify the meaning of a linguistic sign. In subjective-objective theories, the objective approach is supported with a pragmatic linguistic description or a description of real psychological processes taking place while creating and analyzing a linguistic sign. In subjective theories, apart from understanding procedures, there is an emphasis put on the assessment of the results of a user's understanding. It is conducted with the help of feedback in a dialogue or a reflection in a monologue.

It is necessary to state that understanding has elements of logic and rationalism. To understand is to comprehend, know and be aware. PWN dictionary [2] defines understanding as one of forms of thinking, which consists in grasping the sense of phenomena and objects due to the cognition and acquisition of rules (Fig. 2.). Comprehension is noticing order and tidiness in spontaneity, unpredictability or even in chaos. It is not only reason which works here but sensitivity, intuition and inspiration 
Table 1

Sample fragments of dialogue, which may be considered by user for the incomprehensible.

\begin{tabular}{|c|c|c|}
\hline $\begin{array}{l}\text { Application } \\
\text { software }\end{array}$ & Dialogue structure fragment & $\begin{array}{l}\text { Problems with } \\
\text { understanding }\end{array}$ \\
\hline $\begin{array}{l}\text { Skype } \\
\text { (on iPad) }\end{array}$ & $\begin{array}{l}\text { App: Contacts } \\
\text { User: All Contacts or iPad Contacts or Online } \\
\text { Contacts or Saved Phone Numbers or Skype Contacts }\end{array}$ & $\begin{array}{l}\text { What is the difference } \\
\text { between the groups of } \\
\text { contact? }\end{array}$ \\
\hline $\begin{array}{l}\text { SHOUTcast } \\
\text { (on iPad) }\end{array}$ & $\begin{array}{l}\text { User: Favorites }\langle\text { Select station }\rangle \text { Play } \\
\text { App: Server Full }\end{array}$ & $\begin{array}{l}\text { What does it mean for } \\
\text { someone who wishes } \\
\text { to listen the radio? }\end{array}$ \\
\hline $\begin{array}{l}\text { Gmail } \\
\text { (in Google } \\
\text { Chrome } \\
\text { on PC) }\end{array}$ & $\begin{array}{l}\text { User: COMPOSE Message SEND } \\
\text { App: Did you mean to attach files? You wrote } \\
\text { 'Attached files' in your message, but there are no files } \\
\text { attached. Send anyway? } \\
\text { User: Cancel or OK }\end{array}$ & $\begin{array}{l}\text { What will happen to } \\
\text { my message if I click } \\
\text { Cancel? }\end{array}$ \\
\hline $\begin{array}{l}\text { Dia (under } \\
\text { Ubuntu } \\
\text { on PC) }\end{array}$ & $\begin{array}{l}\text { User: Close Diagram } \\
\text { App: Closing diagram without saving. The diagram } \\
\text { '/home/ws/Diagram1.dia' has not been saved. Save } \\
\text { changes now? } \\
\text { User: Cancel or Discard Changes or Save } \\
\text { User: After Discard Changes Quit Dia } \\
\text { App: Quitting without saving modified diagrams. } \\
\text { Modified diagrams exist. Are you sure you want to } \\
\text { quit Dia without saving them? } \\
\text { User: Cancel or Quit }\end{array}$ & $\begin{array}{l}\text { 1. Which changes will } \\
\text { be discarded? } \\
2 . \text { What will be saved? } \\
\text { 3. Why is it asking } \\
\text { about quitting, if } \\
\text { a user discards } \\
\text { changes? }\end{array}$ \\
\hline $\begin{array}{l}\text { LibreOffice } \\
\text { Writer (under } \\
\text { Ubuntu } \\
\text { on PC) }\end{array}$ & $\begin{array}{l}\text { User: File Open Example.doc } \\
\text { User: File Save As Example.docx } \\
\text { App: This document may contain formatting or } \\
\text { content that cannot be saved in the Microsoft Word } \\
2007 \text { XML file format. Do you want to save the } \\
\text { document in this format anyway? } \\
\text { User: Keep Current Format or Save in ODF Format }\end{array}$ & $\begin{array}{l}\text { What is the current } \\
\text { format: DOC or } \\
\text { DOCX? }\end{array}$ \\
\hline
\end{tabular}

as well. Comprehend is to embrace by reason, penetrate with a thought, and to be aware of something, understand.

It is worth reminding that in colloquial language word sense may be a simple synonym of the word meaning. In the context of taking up an activity, the sense is often a synonym of the aim of this activity. A deeper meaning of the word sense may generally be divided into: cognitive sense, which can be related to experience and pragmatic sense, which cannot be related to experience but it brings some visual images and it induces actions.

An analysis of Polish publications concerning this phenomenon show, there is a noticeable linguistic dichotomy of understanding and comprehension as a terminological division of the phenomenon into two complementary parts. The same division is visible in other languages e.g. in English publications there is the term comprehen- 


\section{Mechanism of understanding}

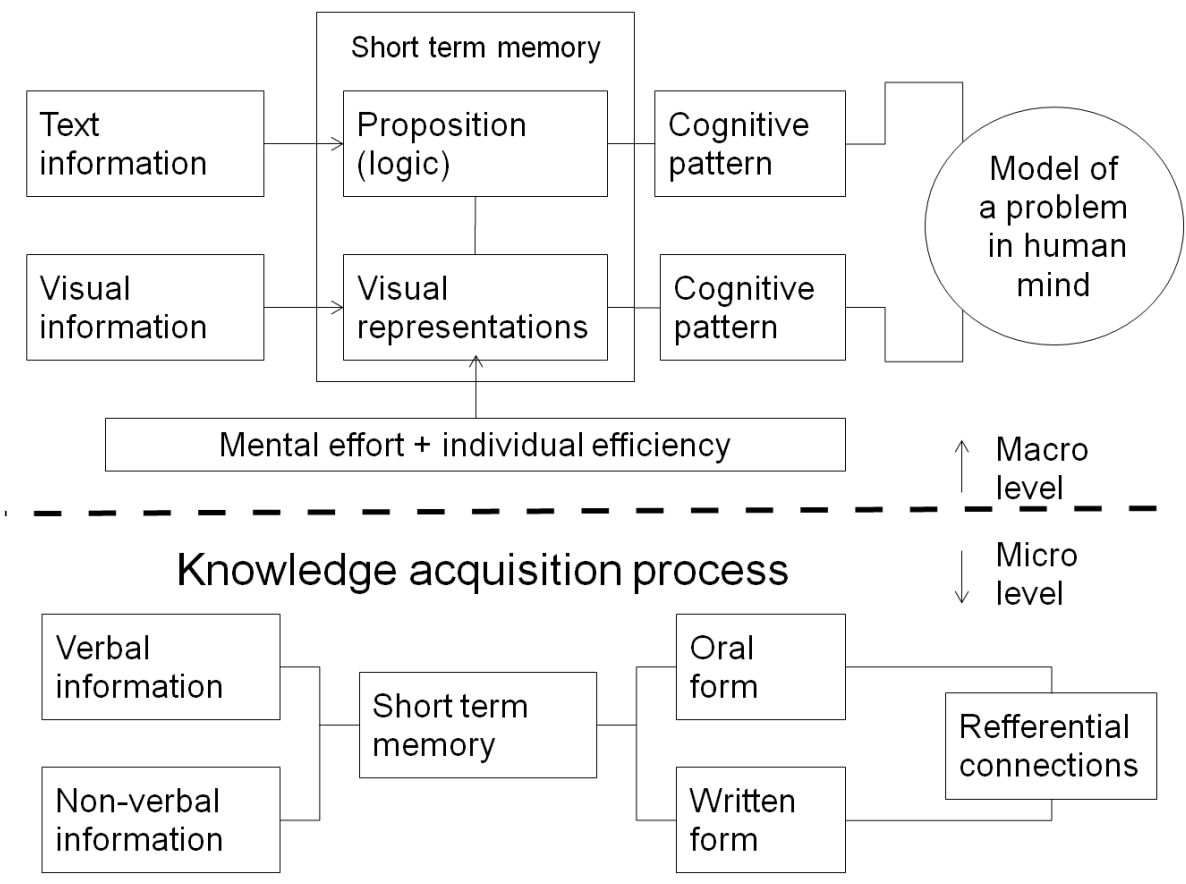

Figure 2. Conceptual diagram of the cooperation of the mechanism of understanding and the process of knowledge acquisition by an individual, on the basis of article [10].

sion - understanding, reasoning, ability to comprehend, ability to grasp, cognition, but also understanding - understanding, comprehension, agreement, acceptance, knowing/familiarity. Analogically in Russian beside the term ponimanije there are osoznanije or usvojenije. Within this article the author does not attempt to introduce this differentiation but uses exclusively the term understanding.

In psychology there is yet another term apperception which specifies the ability to perceive and understand, leading to the acquisition of new information. From the perspective of the psychological sciences apperception is a process during which we acquire new information thanks to the accumulated old ones. It is one of fundamental features of the psyche of a person, which expresses itself by conditioning the perception of objects and real world phenomena and by being aware of this perception by the general matter of psychological life as a whole, by the gathered knowledge and by the state of a specific individual.

The narrower but all important issue of understanding linguistic communiqués is not a scientific novelty because understanding is one of fundamental phenomena of thinking. Examining such a universal category may be observed in different areas 
of science. And thus the analysis of the problem of understanding may be found in linguists' dissertations $[28,12]$ one of them being connected with the problem of artificial intelligence, and in pedagogists' papers connected with searching the optimum didactic solutions.

Due to the fact that understanding is an interdisciplinary category, there are various approaches to its examination. Even the term proper is treated ambiguously. Depending on the authors' views, it is sometimes defined as the interpretation or perception, which is probably unacceptable in the context of the usage of information systems. What is most frequently needed is the knowledge about how the user understands, and not interprets or perceives, the dialogue carried out with a system. It is noticeable that within the frame of existing theories, objects of understanding and ways of describing the process of understanding are defined ambiguously.

When specifying the process of understanding theoretically, such terms as diagrams, frames, scripts are used. Mechanisms of understanding cover: association (associating), recognition, receiving derived knowledge, deeper predication, semantic changes, and forecasting. The holistic reception of a form and linguistic meaning of a sign is emphasized during a constant cooperation of ascending and descending processes of identification with the products of previous experiences. It is suggested that the first word of a communiqué plays the commencing role because it updates a system of associations in a linguistic net and the encyclopedic knowledge of an individual.

It is significant that the reception of a communiqué is not always accompanied by its understanding. Professor Luria identifies two stages of decoding a textual communiqué: the perception of the marked one and the perception of the marking one. The first stage is connected with processes giving a guarantee to decipher the received linguistic codes, and then the second stage connected with a deeper sense hidden behind the received communiqué [19]. The reason for diversity in the interpretation of the communiqué is, among other reasons, the ambiguity of the semantics of a text.

It should be noted that while interpreting a communiqué in the mind of the addressee there might be conditions causing cognitive bias, which conditions causing the occurrence of cognitive distortions. In other words, providing the IS user with the matter of even the highest quality dialogues does not guarantee a rational way of the perception of functions and actions of the system.

It should be emphasized that understanding a written language (text) is considerably different from understanding images, objects or features of personality. The specificity of a text understanding process relies on performing complex work in result of which out of the whole of communiqué there emerges the main thought. The analyzed communiqué is as if compressed in the addressee's internal monologue to form a certain set of senses. It works by the way of compressing the communiqué to a thematic meaning, which is a specific inner code, an equivalent of the contents of the received text. As a result of the process of cognitive processing of textual information in the reader's mind, there appears a certain model of the text which looks like a set of thematic semantic points (views) which is the sense of the received communiqué. 
While describing the phenomenon of understanding, it is difficult to disregard the term insight. Insight is a sudden, holistic, involuntarily and directly from the past drawn understanding of significant relations and structure of an issue. A sensible solution to a problem is achieved via insight. It is often an unexpected shift of perception of a problem, leading to a deeper and fuller understanding. The PWN dictionary defines insight as a phenomenon appearing in troubleshooting tasks, in which learning comes out of (frequently sudden) understanding relations, and not because of random trials.

Herbert Simon juxtaposes the colloquial understanding of insight as recognition of the constructive approach. He thinks [26], that insight is possible due to two parallel processes: taming a problem and selective forgetting. Taming is the gradual learning the structure of a problem in order to simplify its description. With taming, the problem becomes increasingly simpler. In turn, thanks to selective forgetting one gets rid of irrelevant elements of the problem. This process is based on ignoring information which is not important or introduces chaos, information noise. The combination of these two actions makes the problem simple enough to store and cover it in the shortterm memory.

Janet Davidson and Robert Stenberg think [11] that the mechanism of insight is down to selective performance of three operations: coding, comparison and combining. Selective coding is separating important and unimportant information. Very simple tasks cause difficulties to the doer if their description is full of irrelevant information. Selective comparison is relating the newly gained information to the already gathered knowledge. Insight occurs when the addressee is able to associate processed information with something he/she has already known for a long time. Selective combination leads to insight if two or more pieces of information are combined in an unusual way, creating a new relation between the already previously known elements. Each of the three operations may lead to insight, although the probability of the occurrence of this phenomenon increases when all three operations are performed simultaneously.

\section{Understanding textual communiqués in the context of information system}

The phenomenon of understanding, examined as a whole by researchers representing psychology, didactics and sociology in the context of solving communication problems, teaching and professional performance, should also be taken into account by computer engineers - designers of information systems and designers of users' interfaces. This need has become urgent recently as there is a users' growing demand for fast, conscious and efficient use of a greater amount of outer knowledge, present in different forms, from books to web sites.

Yet in the 70s it was established [25], that to be able to work efficiently with a new system or code, a programmer must understand five levels of abstraction: function, data flow, steering flow, operation, and state. The research in question defines 
understanding and mastering all five abstractions. Since the model works for any given type of software, it does not refer exclusively to the specificity of a programmer's mind. It focuses more on the functionality of software, therefore the model may relate to almost any computer user. Lack of awareness of this standard, in the context of the assessment of the abstraction, may bring numerous cognitive inaccuracies while explaining complex ideas.

In the context of a user's interaction with a new interface of an information system, understanding has a practical meaning, most importantly as an acceptable result of semantic perception of linguistic content. In this sense, objects of understanding are system events and communiqués written by the system (messages, information, announcements, reports, applications, and forms).

At the level of abstraction relating to linguistic signs one may claim that an individual understands an expression (a statement, a view), when he/she perceives them correctly, which means that he/she knows the sense of this expression (see the previous subchapter). The term sense in the definition of understanding a linguistic sign is used here in the strict meaning, as an indicator of fulfilling certain pragmatic or semantic functions by a certain expression. The users of expressions, forming a dialogue carried by with an IS are in fact designers (authors of communiqués) and end users (addressees of the communiqués) of a system. An IS user, as an addressee of a certain expression understands it when he/she knows its semantic and pragmatic functions.

When users of a given linguistic expression understand it, one may say that there occurs a pragmatic relation between the sender and addressee of the expression as a result of understanding the expression in question. In this situation it is a pragmatic relation between a designer and the target IS user. The success of introducing an information system may be based on the occurrence of such relations, characteristic for a problem domain and a specific IT project. One of significant obstacles in achieving this success is the already mentioned ambiguity of the semantics of a text, which comes into being as a result of the realization of individual strategies of understanding. It has to be accepted that independently from the text there are its different mental images in an author's and the reader's mind, not necessarily identical with the text. This phenomenon is known in philosophy and allows us to take into account the most general associations and rules characteristic for governing all phenomena in the world and in thinking. In cognitive science, on the basis of this phenomenon, there is a predictable generation of conceptual systems and operating with types of knowledge. In psycholinguistics the same applies to a text and oral and thinking specificity of an individual. From a computing point of view, it can be said that there is an individual and independent mapping of information about the object of understanding. In this sense, a text, as an object of understanding, objectively has the feature of being prone to interpretation, the interpretability feature of a text conveying objective content, is the basis for further subjective interpretation.

In practice there is always a diversity of the interpretation of a text by readers, which is an manifestation of the already mentioned semantic ambiguity [17]. A re- 
peated set of reactions was noticed in the research concerning the diversity of interpretations, characteristic for a given individual and showing a stable strategy of understanding a text by a given addressee. There have been discovered two main ways of building sense of a text read by a reader - a generalization with ignoring some details and separating a dominating sense component on the way to rebuilding the hierarchy of elements of the contents. This confirms once again that the direct result of the phenomenon of understanding is the acknowledged sense of a communiqué, not the subject matter or contents.

It is worth drawing attention to the possibility of organizing for the IS user a dialogue in the environment of rational perception. It is to be a constructive process in the sense that it is to formalize the deepest and hidden side of the phenomenon of understanding according to the rules of visual methods - in the form of a construct. This construct, in opposite to a natural language is a formal language, specific for a problem domain. In a dialogue with the user both languages are present, which means that the designer should understand both of these bonded languages [20] in order to work out a correct dialogue.

An engineering approach to designing dialogues with the user is to be based on the logical analysis of the content of the communiqués. There is a need to broaden the tool set of this analysis with another term - a proposition (Latin: propositio). A proposition in the logical sense is the meaning of a sentence in the logical sense. The proposition is a semantic invariant for all members of modal and communication paradigm and derivatives from the specific sentence structure. The propositions are equipped with a feature of being true or false, similarly to sentences. A given subject is a proposition, if it has the following characteristic features: independence from a language - different linguistic expressions may represent one proposition, and having a stable logical value, independent of the pragmatic context - the circumstances of delivering a specific statement influences the proposition expressed by the statement but it does not influence the logical value of the proposition itself.

An engineering approach to the matter of a dialogue with the IS user should take into account the structure of a text as well. Noam Chomsky distinguished two perspectives of the examination of a linguistic text structure [8]: deep structure which is the meaningful content (conveying the meaning) of a particular text and a surface structure which stands for the form of the text (words, phrases, inflectional forms and syntax constructions used in the text). The relation between these structures is called linguistic style. In practice, the analysis should cover not only the hierarchical structure of a dialogue but also the causative and logical structure of the text forming a dialogue.

\section{Problem of gradation of understanding}

It is known $[5,23]$, that understanding of linguistic expression is gradable. One may say about a degree, a level or about the depth of understanding of a specific expression. It is said that the bigger the user's awareness of semiotic functions of a specific linguistic 
sign the better the degree of understanding of it. In other words user's understanding of a certain statement increases together with the amount of his/her knowledge and associations it provokes. As a result, the better a user's understanding of a statement, the more he/she is able to know (associate) its consequences. The user understands a given name better, the more he/she is able to be conscious of other names in which it is contained and with which it is associated.

One may single out, in this sense, a subjective criterion of understanding linguistic expressions as a feeling that a certain expression is understood. Then, an objective criterion of understanding is the ability to introduce changes to the expression. Although a subjective criterion of understanding is not available to outer observation, it is worth considering it as a necessary, although not sufficient condition, to achieve full understanding. In this sense, successful acceptance tests (IS tests with representatives of the end user) may be treated as a necessary condition of a well designed dialogue. While an objective criteria may provide digital indicators of the quality of a dialogue. Unfortunately, it would be naive to expect the possibility of this kind of measurement within the frame of typical processes of software production. Such measurements should be carried out as additional research going beyond the assumed production process.

Understanding, in the professional activity of designers and users of the information systems, cannot be described as a simple two-phase phenomenon characterized by going from the state of not understanding into the state of understanding. Understanding is to be regarded as a cyclical process consisting of an analysis and synthesis, containing the distinction of semantic milestones and a combination of all of them into the holistic thinking process, directed to solving an individual's tasks [23]. Understanding at the entry level is an analysis, but at the very moment of the beginning of understanding is always a synthesis, combining parts into a whole. Keeping that in mind, understanding may be interpreted not only as a process, but also as a result of cognitive processes.

During communication in the relation human-computer understanding linguistic expressions are generally not expected because of numerous reasons. Lowering the level of the complexity of communiqués, which is making them more legible is definitely an efficient strategy increasing the degree of understanding. This strategy may be carried out at the stage of designing dialogues with the user. An advantage of user professional interfaces is to be succinct in vocabulary, lack of idiomatic expressions and avoid sentences of complex, ambiguous or unorthodox structure.

The depth of understanding may be characterized by specifying degrees or levels of understanding, as well as by differentiating the stages of the process of understanding. With the first approach, the depth of understanding may be depicted by the level of the concepts which are reached by the IS designer. At the entry level one may differentiate in the subject only a certain accidental feature or functionality, which is planned to be put into practice by the designer. But further on the designer progresses to higher levels of understanding, exploring such aspects of the subject matter as: 
- Relating the currently learned feature or function to a general, well-known category;

- Differentiating the specificity of the currently learned feature (function) in an analytical process;

- Progressing from the holistic reception to detection, analysis and synthesis of the (integral) parts of a system, events (in the system sense), process, object;

- Establishing (with the help of induction and deduction) cause-effect relations and logical relations between analyzed objects and actors (the users of the system).

The depth of understanding is not depleted by the difference in the levels of understanding. Clarity may be introduced as the second important dimension of understanding. It is to convey the dynamics of understanding at each level. This dynamics may be divided into stages:

- Introductory understanding - at the level of slogans;

- Vague understanding - feeling, not cohesive;

- Subjective understanding - achieved, but not yet verbally expressed;

- Active understanding - understanding which can be conveyed to another person in an oral or written form.

\section{Dialogue with an information system as a discourse}

In the circumstances of communication between the user and IS, a text of a dialogue reflects the reality in an indirect way, because it is the world of virtual images, recorded via linguistic signs. Every addressee has an individual linguistic competence, thesaurus, habits and practice. As a result, there is no guarantee that each addressees will have identical semantic references and referential environment. If a dialogue is led between a user and a system, one may picture this as a written variation of a discourse, then one may attempt to transfer onto it the main regularities detected during the examination of the phenomenon of understanding cohesive texts. The process of understanding may be regarded as a specific interpretation which is creating one's own inner text in something analogical, but not identical with the original both in form an in content.

Modeling a strategy of processing a cohesive text [27] has gone through a long way from understanding specific words, through understanding single clauses and to understanding the highest structures of a text. It turned out that e.g. understanding a function of a word in a statement depends on the function structure of a sentence as a whole, encompassing the syntactic and semantic levels. In this way between complex and simple units of a cohesive text there is a positive feedback. An objective verification of the level of understanding of a text occurs on the way of an analysis generated by the addressee of new texts on the basis of acquired texts. Unfortunately, in case of designing dialogues for IS, receiving the process of understanding as an addressee's ability to generate new texts on the basis of the already acquired ones, does not give enough indications as to the design(ing) decisions, concerning the dialogue 


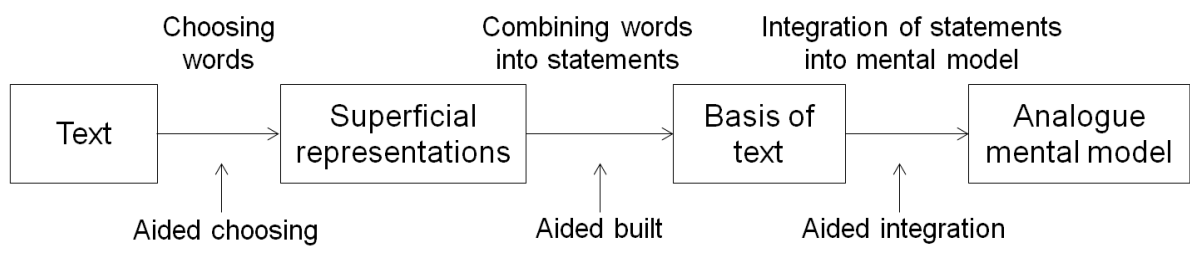

Figure 3. Conceptual model of the process of understanding a text on the basis of an article [22].

with a user. After all, the content uttered by the user in this dialogue is static, imposed by the designer like the context of its utterance. The specificity of a dialogue in computer applications is that a user is limited to statements of the following type: "Yes, print a report" or "Change the type of work into..." or "I accept the setting of parameters", which means he/she should choose a ready-made answer or one of available defined actions.

The interpretation of the understanding of a dialogue as a subjective perception of sense and meaning of deciphered communiqués may turn out to be more efficient. Then, the main result of the dialogue becomes the user's state of awareness, occurring thanks to this dialogue. This state is recorded by the user (subject) as certainty of consonance of recreated ideas. In theory two different mechanisms of such understanding are expected: shaping concepts or immediate creating structures - insight.

Shaping a concept is a complex process as a result of which the concept gains sense, a specific meaning in an individual's consciousness. On one hand a concept, because of its generality, is in modern culture the optimal means with which people understand one another. On the other hand, the generalization contained in a concept creates a wide range of variations of images appearing during attempts of understanding. In this sense concepts do not necessarily have to be understood unambiguously.

Understanding a cohesive text is defined by Chan and Plass [9] as a process of the structurization of mental representations of textual information. According to the author of this publication, first the structure of a text is analyzed at a linguistic level and then representations of statements of semantic structure of the text are created. Finally, the reader constructs a mental model of an object using a diagram. Within the frame of a model of understanding Mayer's text, the authors [9] are able to analyze the usefulness of multimedia information in relation to advanced cognitive processes. According to Mayer [22], there is sense in three categories of supporting the process of understanding a text, presented in form of conceptual diagram in Fig. 3:

- Helping in the choice of information, which is to concentrate the reader's attention on certain aspects of target information;

- Helping in building inner coherence;

- Helping in building outer coherence. 
A situation should be mentioned separately when the users have to take advantage of an information system which is not fully localized. While reading a communiqué in a foreign language there emerges an additional problematic situation of logic-semantic gap in the information chain of the communiqué. This situation occurs as a result of a contradiction between the author's text and its reception by the person reading it.

As far as understanding foreign texts is concerned within the frame of a dialogue with IS it may be stated that the necessity of translation of communiqués definitely hinders understanding. At the first stage of the perception of not localized interface there is the mere establishment of the meaning of words suitable for the context of a specific system and also becoming aware of the syntactic structure. There is a possibility to differentiate a wider period of entering the system due to which there is an anticipation of the content based on the practice and knowledge already possessed by the user. Further on there comes the specification and differentiation of the meaning of the words.

Establishing a new contextual meaning of words is achieved while joining words into phrases on the basis of semantic milestones. During this time an attempt to understand difficult words through deducing hypothesis and guessing is crucial. It leads to the appearance of logical sequences of thoughts, besides which the anticipation becomes correct or without major mistakes. It is the stage of vague understanding in the classification of clarity of understanding. At the stage of direct understanding of communiqués in the consciousness of the addressee all meanings of a word are joined together into a coherent meaning. Reception and thinking are united and inseparable. It is subjective thinking identified as an achieved understanding but not expressed verbally.

\section{Making understanding easier by the improvement of the clarity of the text}

In the new economy based on knowledge, reading still remains the most efficient human activity essential to transform information into knowledge. Trained readers presently read texts with the speed of over 1000 words per minute with almost $85 \%$ of understanding, but they constitute only about $1 \%$ of readers [3]. Average readers achieve the speed of about 200 words per minute with a typical level of understanding of $60 \%$.

After calculating an efficient speed of reading, which is the speed of reading weighed foot of understanding, the result of an average reader is about 120 efficient words per minute. In a research it was also discovered [3], that from the age of 12 most readers do not significantly increase their efficiency of reading. Therefore, it may be assumed that it is the proper speed, if one takes into account the average speed of speaking which is 150 words per minute.

The technical factor of readability of a text $[14,15,13]$ is defined by easiness of reading which is the result of the style of writing. Researches showed that an easy 
text improves understanding, retention (a skill of remembering), speed and durability of reading. Studies on readability of a text provide information on the usefulness of the comparison of the text content, both from the semantic and syntactic point of view, for both a specific circle of addressees as well as for the scope of the levels of competence.

Formulas of readability, tests of readability or factors of readability are patterns of assessment of text readability, usually based on counting syllables, words and sentences. Studies on readability are often used as an alternative to carrying statistical surveys of real readers of a given text. Some text editors incorporate readability tests, which may be used while editing files. These tests generate assessments such as statistic mean of the word length - an indicator of semantic difficulty or the length of a sentence - an indicator of the complexity of the text syntax. There are also several specialist computer programs to measure text readability. Some of them are available on-line on the Internet, and others are especially designed to measure the readability of web sites.

Some of the readability formulas refer to a list of words classified according to their difficulty (complex or multi syllable). It is an attempt to overcome the fact that some words are familiar and readable even for younger children but have many syllables. In practice, however, using simpler words and limiting the length of a sentence make texts more acceptable for readability patterns. Grades obtained in readability tests are often compared to the scale based on a recognized linguistic difficulty or on the level of the class of reading.

From the point of view of functioning of cognitive mechanisms, the easiness of reading is a result of an interaction between a text and a reader. On the side of a reader, readability is influenced by: knowledge gained before, the skill of reading, interest and motivation. On the side of the text these elements are: content, style, design and structure. The design may consist of medium, format, illustrations, elements supporting reading and navigation, font and color. The appropriate use of format, interspaces, width of columns, a contrast of colors of the text and background, spaces, makes the text more readable.

On the basis of the author's own carried out experiments on text readability from the screen of a monitor, he may draw the conclusion that as long as the readability formula does not take directly into account semantic and syntactic complexity, it may not be considered as an ideal tool to measure readability.

\section{Conclusion}

Roland Barthes introduced a unique category readerly text (fr. texte lisible, ang. readerly). In his opinion a readerly text - a text which can be read, is the one in which the reader does not need to create his/her own meanings which could disturb the perception or introduce contradiction. Barthes compares readerly texts to cupboards in which meanings are put, sorted and saved [6]. The addressee of a readerly text is passive to a great extent and his/her active effort is not required. A readerly text 
is fully complete at the moment when it reaches the target user. The work of the integration of all the necessary fragments has been done by the designer of a dialogue, and the user may peacefully work on his/her tasks.

In light of Barthes's model it seems that the texts of the dialogues with the IS user should be built as readerly texts. In this sense they should not introduce new terminology for the target user. They should be limited to the professional vocabulary. So they should be as little informative as possible, not teaching the user but rather reminding him/her of the already known actions possible for the given context and indicating familiar entities and processes. They may give professional clues, not allowing for a teaching style. The semantic side is to be known and unambiguous. It is achievable by creating and consistent use of domain lexicon, in which each word (linguistic sign) is to be checked from the perspective of semantics and pragmatics. The use of words outside of design lexicon is to be not recommended and may be easily controlled by automatic procedures in a design environment.

\section{References}

[1] 1pt plus 1pt

[2] Słownik języka polskiego PWN. http://sjp.pwn.pl/. online, entrance: 2012.

[3] Speed reading test online. http://www.readingsoft.com/. online, entrance: 2012 .

[4] Три парадигмы понимания: анализ литературы вопроса. http://konf-csu.narod.ru/ze/lib/vasilyev.html. online, entrance: 2012.

[5] Ajdukiewicz K.: Logika pragmatyczna. PWN, 1975.

[6] Barthes R.: The pleasure of the text. Trans. Richard Miller, Straus, and Giroux, 1975.

[7] Bidgoli H.: Intelligent Management Support Systems. Quorum Books, 1998.

[8] Chomsky N.: Language and Mind. Harcourt, Brace \& World, 1968.

[9] Chun D., Plass J.: Research on text comprehension in multimedia environments. Language Learning \& Technology, 1(1):60-81, July 1997.

[10] Chun M.: Research on text comprehension in multimedia environments, volume 1. 1997.

[11] Davidson J., Stenberg R.: The nature of insight. MIT Press, 1996.

[12] Демьянков, В. З.: Интерпретация, понимание и лингвистические аспекты их моделиорования на ЕБМ. Изд-що МГУ, 1989.

[13] DuBay, W. H.: The Principles of Readability. Impact Information, 2004.

[14] DuBay, W. H.: Smart language: Readers, Readability, and the Grading of Text. Impact Information, 2006.

[15] Fry E.: Readability versus leveling. Reading Teacher, 3:286-292, 2002.

[16] Gibson, J. J.: The Ecological approach to Visual perception. Lawrence Erlbraum Associates, 1986. 
[17] Кирсанова, И. Ш.: Роль реакций «мниения» и «оценки» при построении реципиентами «встречного текста» в процессе понимания речевого произведения. pages 131-136, 2007.

[18] Kusztina E., Różewski P., Susłow W., Królikowski T.: Metafory komputerowe w e-kursach. e-Mentor, 4:18-23, 2007.

[19] Лурия, А. Р..: Язык и сознание. Изд-що МГУ, 1979.

[20] Малиновская, К. В..: Пониманиые и его роль в науке. Философиские науки, (1):49-55, 1974.

[21] Sugumaran V.: Intelligent Support Systems: Knowledge Management. 2002.

[22] Mayer, R. E.: Aids to text comprehension, vol. 19. 1984.

[23] Наролина, В. И.: К проблеме уровней понимания. Вопросы психологии, (6):125-126, 1982.

[24] Norman, D. A.: The Design of Everyday Things. MIT Press, 1998.

[25] Pennington N.: Comprehension Strategies in Programming. Ablex Series Of Mono-graphs, Edited Volumes, And Texts archive. Empirical studies of programmers second workshop book contents, 1987.

[26] Simon, H. A.: Explaining the Ineffable: AI on the Topics of Intuition, Insight and Inspi-ration. Number 1. IJCAI (1), 1995.

[27] Van Dijk, T. A., Kintsch W.: Strategies of discourse comprehension. Academic Press, 1983.

[28] Залевска, А. А.: Текст и его понимание. Изд-во ТГУ, 2001.

\section{Affiliations}

\section{Walery Susłow}

Department of Electronics and Computer Science, Koszalin University of Technology,

Koszalin, Poland, walery.suslow@ie.tu.koszalin.pl

Received: 24.05 .2012

Revised: 7.07.2012

Accepted: 3.09 .2012 